\title{
Refresher Training on Maternal and Child Health for Urban Community Health Volunteers: Assessing Knowledge and Skills
}

\author{
Joshi HS ${ }^{\dagger}$, Joshi MC ${ }^{*}$, Ranjan $\mathbf{P}^{\dagger}$, Misra $S^{\dagger}$, Verma $\mathbf{P}^{\dagger}$, Rana MSS $^{\dagger}$, Agarvanshi $\mathbf{G}^{\dagger}$ \\ ${ }^{\dagger}$ Department of Community Medicine, Manipal College of Medical Sciences, Nepal \\ *Institute of Medical Sciences, BHU, Varanasi (UP), India
}

(Received 12 December 2005 and accepted 03 February 2006)

\begin{abstract}
Refresher training is given to the health volunteers/workers for updating and upgrading the knowledge \& skills to deliver comprehensive and integrated services and to increase female involvement in the healthcare delivery system and also to develop selfhelp mechanisms at the community \& family level. This study was carried out to understand the effect of Refresher training course on the knowledge and skills of Urban Community Health Volunteers (UCHVs) on Maternal and Child Health (MCH). The course was conducted by the Manipal College of Medical Sciences at the Manipal Teaching Hospital and Manipal School of Nursing, Pokhara, Nepal on seven days during the month of August, September and October' 2005. The Manipal Teaching Hospital is a tertiary care hospital catering for a large population in a hilly area in the western development region of Nepal. The numbers of Urban Community health volunteers were 56 . Semi structured questionnaire with precoded closed and open ended questions in Maternal and child health were used before and after the training period. After the completion of the course, there was a significant increase in knowledge and skills of the volunteers ( $\mathrm{Z}$ value=13.3, $\mathrm{p}<0.001$ ). The course could be conducted adequately using the material and methodology proposed, but could have been more satisfactory if the time allocated to the exercise and clinical practical sessions were increased. The study also highlighted the need for involving and encouraging health institutions in the private sector for the development of suitable training policy of His Majesty's Government and also in the implementation of national strategies for health for all.
\end{abstract}

KEY WORDS: Maternal and Child Health, Refresher Training, Urban Community Health Volunteers, Breast Feeding, Acute Respiratory Infection, Diarrhoeal Disease.

INTRODUCTION: The term "maternal and child Health" (MCH) refers to the promotive, preventive, curative and rehabilitative health care for mothers and children. It includes the subareas of maternal health, child health, family planning, school health, handicapped children, adolescence and health aspects of care of children in special settings such as day care centers ${ }^{1}$.
The specific objectives of MCH are:

- Reduction of maternal, perinatal, infant \& childhood mortality \& morbidity.

- Promotion of reproductive health.

- Promotion of the physical and psychological development of the child and adolescent within the family.

Corresponding Address: Dr H S Joshi, Assistant Professor, Department of Community Medicine, Manipal College of Medical Sciences, Pokhara, Nepal, E-Mail: drjoshiharish@rediffmail.com 
The ultimate objective of MCH services is life long health ${ }^{1}$. The census of 1991 in Nepal showed that $42 \%$ of the population was under 14 years of age and that $21 \%$ were in the reproductive age group of 15-44 years ${ }^{2}$. Nepal was ranked 144 out of 174 on the 1999 Human Development Index (HDI), indicating a low level of human development as measured by life expectancy, educational attainment and adjusted income ${ }^{3}$. The highly patriarchal nature of the society is reflected by the country's extremely low ranking (121 out of 143) on the Gender Development Index (GDI), a measure of gender disparity in human capabilities ${ }^{3}$. This is lower than Bhutan (119), India (112), and Sri Lanka (76) but higher than Bangladesh (123) ${ }^{3}$.

Similarly, the Gender Empowerment Measure (GEM), representing the participation of women in economic, political and professional spheres, is very low at $0.19^{4}$. The GEM values for Bangladesh, India \& Sri Lanka are 0.30, 0.24 \& 0.32 respectively $^{5}$. Female life expectancy at birth is 57.1 years, lower than that in Bangladesh, Bhutan, India \& Sri Lanka (58.2, 62, 62.9 \& 75.4 respectively) ${ }^{3}$. The life expectancy of female as percent of male is $97.6 \%$ in Nepal ${ }^{5}$. In respect of life expectancy at birth, Nepal is probably one of the only countries remaining in the world where female mortality is significantly higher than male mortality, at all ages. The female adult literacy rate was 20.7 percent, lower than that of Bangladesh, Bhutan, India \& Sri Lanka (27.4, 30.3, 29.4 \& 87.6 respectively) ${ }^{3}$.

The infant and maternal mortality rates in Nepal are among the highest in the world at 75/1000 live births (16) and 539/100000 live births respectively ${ }^{6}$. About seventy percent of women of reproductive age are anemic $\&$ malnourished $^{7}$. Women face harsh condition during pregnancy \& childbirth. Many women get pregnant at a younger age and do not leave adequate space between children ${ }^{8}$. Furthermore, many are forced to do hard labor during pregnancy. Together, these factors have a negative effect on intrauterine growth and the development of the fetus, resulting in underweight infants who are vulnerable to infections.

The role of the urban community health volunteers is mainly focused on:

a) Motivation and education of local mothers and community members for the promotion of safe motherhood, mother and child care, family planning and community health. b) Promotion of available health services, i.e., immunization, family planning, Control of Diarrhoeal Disease etc.

c) Distribution of Family Planning pills, Condoms and ORS packets.

d) Distribution of Vitamin A Capsules.

e) Providing referrals for Acute Respiratory Infections (ARI) and severe diarrhea cases.

GOAL:

The goal of the Refresher training program (RTP) was to upgrade the skills \& knowledge of Urban Community health Volunteers (UCHVs) to deliver comprehensive and integrated maternal \& child health (MCH) services at the community \& family level, specially focusing on progressive reduction of maternal, perinatal, neonatal \& infant mortality rates, over a period of time.

\section{OBJECTIVES:}

The overall objectives of refresher training Program for urban community health volunteers are:

- To empower the health volunteers with basic knowledge of primary health care, especially related to the health of mothers and children.

- To increase the knowledge of volunteers regarding objectives of ANC, high risk pregnancy, bleeding in pregnancy, warning signs of pregnancy, stages of labor and complication of third stage of labor.

- To empower the volunteers with the knowledge of current $\mathrm{MCH}$ problems in Nepal.

- To enhance the volunteers knowledge in intrapartum and postpartum care.

- To address the problems of under-5 diarrhoeal disease, under-5 ARI and Under5 malnutrition.

- To update the volunteers knowledge, attitude and practice regarding nutritional requirement during pregnancy and lactation.

- To provide knowledge and skills regarding breast feeding and weaning and filling of growth chart.

This study was undertaken to determine the impact of Refresher training on the knowledge and skills towards maternal and child health of urban community health volunteers.

\section{MATERIALS \& METHODS:}

\section{Location:}

The Refresher Training for urban community health volunteers of Urban Basic Service Unit of Pokhara Municipality (between ward no 1 to 18) 
was conducted by Manipal College of Medical Sciences at Manipal Teaching Hospital \& Manipal School of Nursing, Pokhara for a period of three days during the month of August, September and October' 2005 in three different batches. (Batch I: Ward no. 1 to 6 volunteers, Batch II: Ward no. 7 to 12 volunteers, Batch III: Ward no. 13 to 18 volunteers).

\section{Training of Urban Community Health Volunteers:}

Training was conducted for three days between 10 a.m. to 4 p.m. The total duration of the training was over 56hrs (8hrs daily for 7 days). The total number of urban community health volunteers was 56 . The subject matter included in the training module was as under:

- Introduction to $\mathrm{MCH}$

- Diagnosis of pregnancy

- Antenatal care

- Bleeding in pregnancy

- Nutritional counseling for pregnant and lactating mothers

- Stages of labor

- Complications of third stage of labor

- Immediate postnatal care of the baby

- Breast feeding and weaning

- Growth charts

- Growth and development of child up to five years

- Care of under five children

- Family planning

- STD/ AIDS

The training methods included brief didactic lectures, small group work including practical sessions, individual lesson planning, focus group discussion \& micro teaching practice. Audio visual aids used for the sessions were microphones, chalk board, leaflets, posters, charts, flannel graph, exhibits, models, specimens, over head projector, slide projector, Televisions \& VCR Projector (Cinema).

VCR projectors were mainly used to teach the volunteers regarding IMCI guidelines for childhood illness. Health Education in the form of Role-play was also included during training period. Parts of the WHO/UNICEF breast feeding counseling course ${ }^{\mathbf{9}}$ were used as guides. Counseling skills were taught by demonstration and role play \& included listening to volunteers, learning about their difficulties \& providing relevant information and practical help when required. The volunteers were also taken to skills laboratory of the Department of Anatomy to show them the development of fetus in the uterus
\& stages of labor using Mannequins. Case studies were arranged in the Pediatric \& OBG wards of the Manipal Teaching Hospital. Adequate interactive sessions were conducted between participants and facilitators to maximize benefits of the training, in the community and family contexts.

\section{Facilitators:}

- Nursing Tutors

- Medical Officers

- Principal, School of Nursing

- Medical faculties of following Departments OBG, Pediatrics \& Community Medicine.

\section{Data Collection:}

Semi structured questionnaires with pre-coded closed \& open-ended questions in $\mathrm{MCH}$ were used before \& after the training period. The questionnaire also included data regarding age, marital status \& literacy status of the participants.

\section{Data Analysis:}

Each participant was provided with a unique identifier to blind the evaluators to the participants' training status. It was decided to take a more detailed look at the data by scoring the answers as follows:

- 2 points for a correct and complete answer,

- 1 point for a correct but incomplete answer,

- 0 points for a missing answer, and

- Deleted 1 point for an incorrect answer.

Performance at each station was assessed by the same evaluator in order to achieve a measure of consistency. Answer to questions were analyzed in Epi info; version 6.0. The data were then verified \& cross checked.

\section{Statistical test used:}

The statistical method used were mean, standard deviation, standard error of difference between two mean, confidence interval and $\mathrm{Z}$ test (using $5 \%$ level of significance to determine if the data indicate a difference in mean score of knowledge \& skills of volunteers before \& after the refresher training program).

\section{RESULTS:}

Fig 1 shows the literacy status of urban community health volunteers. Max number of volunteers had completed their secondary examination (32; 57.1\%), 5 (8.9\%) and 4 (7.1\%) had passed the primary and higher level education (graduate) respectively while 10 (17.8\%) volunteers had passed the lower 
secondary examination. Only 5 volunteers (8.9\%) were illiterate. Fig 2 shows the age wise distribution of urban community health volunteers .The number of volunteers between age group of 20 to 29 years was maximum (23; $41 \%)$ followed by age group of 30 to 39 years (16; $28.5 \%)$. Only $13(23.2 \%)$ volunteers are over the age of 40 years. Table 1 shows the scores of the volunteers before \& after the commencement of refresher training program. The difference in knowledge \& skills of volunteers is said to be significant at less than $0.1 \%$ level. Therefore, there is a significant increase in knowledge \& skills of volunteers on $\mathrm{MCH}$ following the refresher training $(\mathrm{Z}$ value $=13.3 ; \mathrm{p}<.001)$.

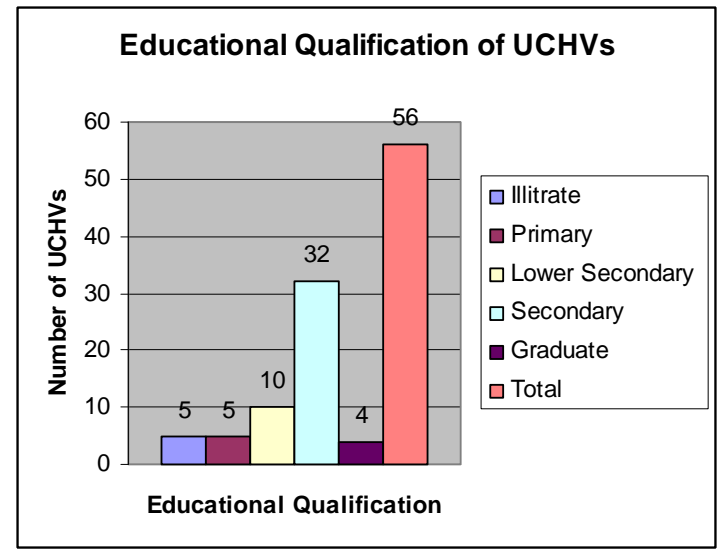

Fig 1

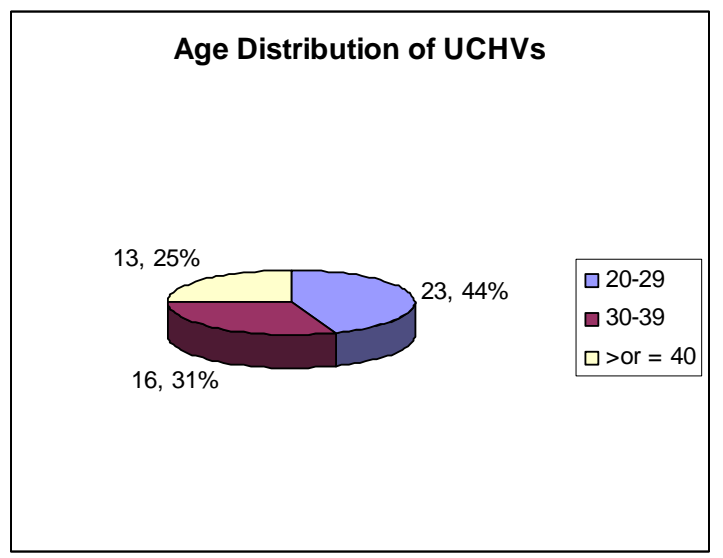

Fig 2

Table 1: Scores of the Urban Community Health Volunteers (UCHVs) before and after the commencement of Refresher training Program $(n=56)$

\begin{tabular}{|c|c|c|c|c|c|c|c|}
\hline Samples & $\begin{array}{c}\text { No of } \\
\text { UCHVs } \\
\text { (n) }\end{array}$ & $\begin{array}{c}\text { Mean } \\
\text { Score (x) }\end{array}$ & $\begin{array}{c}\text { Standard } \\
\text { Deviation } \\
\text { (SD) }\end{array}$ & $\begin{array}{l}\text { Standard } \\
\text { Error of } \\
\text { difference } \\
\text { between } \\
\text { two means } \\
\text { (SE) } \\
\end{array}$ & $\begin{array}{c}\text { Confidence } \\
\text { Interval }\end{array}$ & $Z$ value & Results \\
\hline $\begin{array}{c}\text { Before } \\
\text { Training }\end{array}$ & 56 & 23.5 & 9.45 & \multirow{2}{*}{1.65} & \multirow{2}{*}{$22.1 \pm 3.23$} & \multirow{2}{*}{13.3} & \multirow{2}{*}{$\begin{array}{c}\text { Highly } \\
\text { Significant } \\
(\mathrm{P}<0.001)\end{array}$} \\
\hline $\begin{array}{c}\text { After } \\
\text { Training }\end{array}$ & 56 & 45.6 & 7.60 & & & & \\
\hline
\end{tabular}

DISCUSSION:

Human Resource Development has been an area of priority for the Ministry of Health / Department of Health Services and training has remained an integral part of all programme units since its inception .The current training network includes the National Health Training Center (NHTC), one Regional Training Center (RTC) per region and a Sub-Regional Training Center in the Central Region. To support health training centers in developing the clinical skills of trainee health workers, three to five health posts in each region are being developed as training health posts. The over all goal of the NHTC is to develop a training system capable of responding to the training requirements of all categories of Health Workers to deliver PHC services to support the implementation of the National Health Policy $1991^{10}$.

It is almost impossible for a developing country to employ fully trained graduate physicians for all aspects of primary health care. Since an adequate member of physicians may not be available or be willing to work in peripheral health posts, physicians need to delegate some of the simpler health tasks to the paramedical workers. Increasing dependence on other categories of personnel with limited job training in specific areas of work becomes necessary. Preferably, these urban community health volunteers (UCHVs) are drawn from, as well as, chosen by the community they are expected to serve. Low academic background may not be a significant limitation in their performance as 
shown in the Fig 1. Volunteers are mainly selected from "Mother group" formation on the basis of population to enhance community selfhelp in primary health care through increased knowledge and mobilization of local women \& other resources. They are mainly responsible for promoting community participation. Community participation is a cost effective method for extending the reach of health services to the people ${ }^{11}$.

"Program evaluation" is a process of making informed judgments about the character and quality of an educational program or parts thereof ${ }^{12}$. The assessment of knowledge and skills of urban community health volunteers after refresher training course indicate that it was well received (Table 1). The refresher training is given to the health volunteers/workers - for updating and upgrading the knowledge \& skills to deliver comprehensive and integrated maternal \& child health services, to increase female involvement in the healthcare delivery system and to develop self-help mechanisms at the community \& family level. The trainers placed particular emphasis on clinical as well as counseling skills. Particular emphasis was given to the newborn care as $50-60 \%$ of the infant deaths occur during the neonatal period in the developing countries ${ }^{13}$. These include harmful traditional practices, inadequate health/medical care, inability to recognize the danger signals in the sick newborn, lack of transport facility for accessing emergency care, poor maternal health, failure to promote early and exclusive breast feeding and so on ${ }^{14}$.

Studies have demonstrated that community health guides, traditional birth attendants (TBA) \& village level health workers can also be trained effectively for identification and domiciliary management of high risk babies $^{15,16,17,18,19}$. The volunteers were also trained on IMCI strategy, which combines the improved management of childhood illness with emphasis to nutrition, immunization \& other important factors influencing child health, including maternal health. In an attempt to reduce under five morbidity and mortality in the developing world \& to improve health-workers performance in managing childhood illness, World Health Organization (WHO) and United Nations Children's Fund (UNICEF) have developed an "Integrated Management of Childhood Illness" (IMCI) approach ${ }^{20,21}$. The Ministry of Health (MOH) recognizes that Acute Respiratory Infection (ARI) and Diarrhoeal Disease (DD) together form one of the major public health problems in Nepal among children less than 5 years (60 months) of age ${ }^{\mathbf{1 0}}$.

Research conducted by John Snow, Incorporated (JSI) in Jumla, Western Nepal concluded that " trained clinicians are not always necessary for effective pneumonia control intervention, that low-literate villagers without previous health knowledge can be trained to detect and treat childhood pneumonia effectively even without other health or referral services, and that this intervention alone can lead to significant overall mortality reduction" ${ }^{22}$.

Knowledge of primary health care, especially related to the health of mothers and children was emphasized such as antenatal care and postnatal care including the Family Planning methods. In Nepal, most women lack access to basic maternity care. Only 27 percent of women seek antenatal care once during pregnancy ${ }^{23}$. Of those that seek prenatal care, the average number of ANC visits per pregnancy is 1.8 , far short of the minimum of four visits per pregnancy that are required $^{23}$.

According to a 1997 survey, a little over a third of surveyed women (34 percent) said that they did not receive ANC because they thought they did not need it. Thirty-one percent said that they did not traditionally receive antenatal care. Twenty four percent of women said they did not know that such services were available. Eleven percent said the health facilities were located too far away and five percent did not have enough money to pay for the services. Two percent of the women did not have time to visit a health facility; two percent said their family members did not allow them to seek care and two percent said they did not seek care because the service was poor ${ }^{8}$.

As for childbirth, most deliveries occurred at home in unsafe conditions. Only 8 percent of births take place at health facilities \& only 13.4 percent of births are attended by trained health personnel ${ }^{23}$. After childbirth, 9 percent of women seek postnatal care ${ }^{23}$. Most maternal deaths occur at home $(68 \%)$ due to a number of factors that could be prevented with skilled and timely attendance during pregnancy and child delivery ${ }^{24}$.

Despite the fact that the availability of public health services has increased throughout the country, health services are still beyond the reach of most rural women. It is reported that only 45 percent of households have access to basic health care $^{8}$. The contraceptive prevalence rate and total fertility rate in Nepal is $34.5 \%$ and 4.64 per women respectively (1996) ${ }^{\mathbf{1 0}}$. 


\section{Limitations of study:}

In all sessions, the major problem in following the course guidelines was lack of time. The lack of time was especially detrimental to the completion of exercises and to clinical practice, both of which are of fundamental importance to the course.

The difficulty in conducting the sessions could be due to the more educated trainers teaching in stereotype manner ignoring the literacy status of volunteers.

\section{CONCLUSION \& RECOMMENDATIONS:}

Despite above quoted limitations, the analysis showed highly significant improvements in knowledge and skills on $\mathrm{MCH}$ of the urban community health volunteers (Table 1).

Despite weaknesses in the urban community health volunteer program in Pokhara, Nepal and inadequate management support, there has been a sharp increase in coverage by the health services.

In the process of human resources development, the National Health Training Center faced acute shortage of training manpower ${ }^{\mathbf{1 0}}$. This problem can be dealt with by involving \& encouraging the "private sector" for the development of training policy of HMG Nepal. Medical schools and academic institutions could play an important role in improving general health services, as they currently do for specialized services.

It is imperative that the female population be involved in primary health care activities, especially in respect to mother and the child care, family planning, immunization, control of communicable diseases and other health promotion activities.

This study has shown that the refresher training course effectively increased the volunteer's knowledge and skills on some specific areas of $\mathrm{MCH}$. Adequate time may have to be considered in future for exercises \& clinical practice, which may further enhance the learning of skills.

\section{REFERENCES:}

1. WHO. Tech. Rep. Ser. No. 600. 1976.

2. Nepal- Fertility, Family Planning and Health Survey. 1991. FP \& MCH Division, Planning, Research \& Evaluation Section.1993.

3. Human Development Report. 1999.

4. Nepal, Nepal South Asia Centre. Nepal Human Development Report, Kathmandu. 1998

5. Nepal Statistical Year book. 1993.
6. India, Regional office for South- East Asia, World Health Organization. Women of South-East Asia, A health Profile, New Delhi. 2000.

7. Nepal, Ministry of Health / UNICEF / WHO / The Micro nutrient Initiative / New ERA Ltd., Nepal Micro Nutrient Status Survey, Kathmandu. 1998

8. Nepal, National Planning Commission / UNICEF, 1998, Nepal Multiple Indicator Surveillance Fifth Cycle (March-May 1997), Kathmandu.

9. WHO. Breast feeding counseling: a training course. Division of diarrhoeal \& acute respiratory disease control, WHO/CDR/93.3-6 and UNICEF/ NUT/ 93. Geneva: WHO, 1993.

10. Nepal, Ministry of Health, Annual Report, Kathmandu. 1999/2000.

11. WHO, Alma Ata 1978: Primary Health Care, HFA Sr. No.1; 1978.

12. F.M. Katz. Guidelines for evaluating a training programme for health personnel: WHO offset Publication No. 38; World Health Organisation Geneva. 1978.

13. Perera T. Perinatal morbidity and mortality trends in South-East Asia. Proceedings of the ASEAN Pediatric Federation Workshop on Perinatal Morbidity and Mortality, Kuala lumpur 6-7 June 1982. In: Abdul Kadir H, editor. ASEAN perinatal health issues, Kuala Lumpur: ASEAN Pediatric Federation: 1983.

14. Stoll BJ. The global impact of neonatal infection. Infect Perinatol. 1997;24:1.

15. Pratinidhi AK, Shrotri AN, Shah U, Bodhani ND. Domicilliary care of low birth weight neonates. Indian Paediatr. 1992;29:189.

16. Daga SR, Daga AS, Dighole RV, Pati RP, Dhinde HL. Rural neonatal care, Dahanu experience. Indian Paediatr 1992;29:189.

17. Daga SR, Daga AS, Dighole RV, Patil RP, Dhinde HL. Anganwadi workers participation in rural newborn care. Indian Paediatr 1993;60:627.

18. Kumar R. Effectiveness of training traditional birth attendants for management of asphyxia neonatorum using resuscitation equipment. Prenat Neonat Med. 1998;3:255.

19. Bang AT, Bang RA, Baitule SB, Reddy MH, Deshmukh MD. Effect of home -based neonatal care and management of sepsis on neonatal mortality; Field trial in rural India. Lancet. 1999;354:1955. 
20. World Health Organization. Integrated management of the sick child. Bull WHO. 1995;73:735-740.

21. Gore S. Integrated management of childhood illness by outpatient health workers: Technical basis \& overview. Bull WHO 1997;75(Suppl I):7-24.

22. Pandey MR, Daulaire NMP, Starbuck ES, et al. Reduction in total under-five mortality in
Western Nepal through community-based antimicrobial treatment of pneumonia. The Lancet 1991; 338: 993-997.

23. Nepal , Ministry of Health, Annual Report (1998/99), Kathmandu. 1997.

24. Nepal, Ministry of Health, Nepal Maternal Morbidity and Mortality study, Kathmandu. 1998.

Internet Journal of Medical Update

ISSN 1694-0423, http://www.geocities.com/agnihotrimed 